\title{
The Association between Number of Tooth Loss, Tooth Loss Quadrants, and Occlusal Support with Temporomandibular Disorders in Partially Edentulous Patients
}

\author{
Ricca Chairunnisa \\ Department of Prosthodontics \\ Faculty of Dentistry, Universitas Sumatera Utara \\ Medan, Indonesia \\ riccachairunnisa@yahoo.com
}

\author{
Ribka Julia Sihombing \\ Student \\ Faculty of Dentistry, Universitas Sumatera Utara \\ Medan, Indonesia
}

\begin{abstract}
Loss of one or several teeth can disturb the balance of the composition of the teeth in the arch that causes imbalance occlusion of teeth so that the teeth will receive a larger load. Stresses imposed by the structure of the temporomandibular joint is imbalance and would interfere with the function of the temporomandibular joint. The etiology of temporomandibular disorder is multifactorial so that the relationship between tooth loss with temporomandibular disorders is a matter of debate in the field of dentistry. The purpose of this study is to determine the relationship between tooth loss and the signs and symptoms of temporomandibular disorders which in terms of the number of tooth loss, the number of tooth loss quadrants, and the amount of occlusal support based on Eichner Index classification. The type of this study is descriptive analytic with cross-sectional design. The study was done in RSGM FKG USU, conducted through direct interviews using questionnaires and clinical examination on 100 subjects aged over 18 years with partial tooth loss. The results showed that the prevalence of tooth loss in part with temporomandibular disorder based on questionnaire is $59 \%$ while based on clinical examination is $86 \%$. There is significant correlation between the number of tooth loss quadrants with temporomandibular disorder, while the number of tooth loss itself and the occlusal support are not associate with temporomandibular disorder. But it was found that there is an increased incidence of temporomandibular disorders along with an increase in the number of tooth loss.
\end{abstract}

Keywords-partially edentulous, tooth loss, occlusal support, temporomandibular disorder

\section{INTRODUCTION}

Tooth loss is a common problem of teeth and mouth. Directly the tooth plays a role in the mastication function and is useful for maintaining the stability of the vertical and distal relationships between the mandible and the maxilla. The loss of a large number of teeth also results in an increase in the occlusal load on the remaining tooth so that in later stages may disrupt the function of the temporomandibular joint $[1,2]$.

Temporomandibular disorder (TMD) refers to a number of clinical problems that involve masticatory musculature, temporomandibular joints, and related structures or both [3]. Loss of occlusal contact results in an occlusion imbalance that will disturb the stability of the dental arch and this condition causes the temporomandibular joint structure to receive a larger load $[4,5]$. The etiology of temporomandibular joint disorder is multifactorial that many risk factors are often associated with signs and symptoms of temporomandibular joint disorders $[3,4,6]$.

The association between tooth loss and temporomandibular disorders (TMD) remains controversial $[7,8]$. Therefore, the authors are interested to investigate whether the number of missing teeth are associated with temporomandibular disorders in RSGMP FKG USU patients in terms of the number of missing teeth, the number of dental quadrants with missing posterior teeth and the number of occlusal support.

\section{MATERIALS AND METHODS}

This study is descriptive analytic with cross sectional design. In this study, respondents were interviewed directly by using questionnaires and clinical examination. The questionnaire used was Fonseca's Questionnaire consisting of ten questions about difficulty opening the mouth, the frequency of headache, neck pain, pain in the craniomandibular joints, the presence of sounds in the joints, articulations and feelings of nervousness or tension experienced.

Clinical examination of the temporomandibular joints using the dysfunction index is based on the evaluation of five clinical signs of joint function disorder and modified mobility index (Helkimo 1974) consisting of: Measurement of maximal mouth opening distance, temporomandibular joint function decline by auscultation and measurement of deviation, muscle pain, Joint pain and pain during mandibular movements. The sample was 100 patients FKG USU RSGMP aged over 18 years with missing teeth partially who has requested his consent through informed consent. The samples were grouped into three characteristics, namely 
the number of missing teeth partially, the number of dental quadrants with missing posterior teeth and the number of occlusal support based on Eichner calcification.

\section{RESULTS}

The obtained data is presented by calculating the percentage of distribution, then tested significantly with chi-square $(p<0.05)$ to test the relationship of two nominal variables and measure the strength of the relationship between one variable with other nominal variables.

TABLE I. CHARACTERISTICS OF PATIENTS WITH MISSING TEETH IN RSGMP FKG USU

\begin{tabular}{|c|c|c|c|}
\hline No & Variables & $\mathbf{N}$ & $\%$ \\
\hline \multirow[t]{5}{*}{1.} & The number of missing teeth & & \\
\hline & $1-5$ & 54 & 54 \\
\hline & $6-10$ & 15 & 15 \\
\hline & $>10$ & 31 & 31 \\
\hline & & 100 & 100 \\
\hline \multirow[t]{6}{*}{2.} & $\begin{array}{l}\text { The number of dental quadrants with } \\
\text { missing posterior teeth }\end{array}$ & & \\
\hline & 1 & 20 & 20 \\
\hline & 2 & 21 & 21 \\
\hline & 3 & 12 & 12 \\
\hline & 4 & 47 & 47 \\
\hline & & 100 & 100 \\
\hline \multirow[t]{8}{*}{3.} & Occlusal support & & \\
\hline & $\mathrm{A}$ & 45 & 45 \\
\hline & $\mathrm{B} 1$ & 7 & 7 \\
\hline & B2 & 18 & 18 \\
\hline & B3 & 7 & 7 \\
\hline & B4 & 10 & 10 \\
\hline & $\mathrm{C}$ & 13 & 13 \\
\hline & & 100 & 100 \\
\hline
\end{tabular}

TABLE II. PREVALENCE OF MISSING TEETH WITH TEMPOROMANDIBULAR DISORDER IN PATIENTS AT RSGMP FKG USU BASED ON QUESTIONNAIRES AND CLINICAL EXAMINATION

\begin{tabular}{|c|c|c|c|c|c|}
\hline \multirow{2}{*}{ Examination } & \multicolumn{2}{|c|}{ Yes } & \multicolumn{2}{c|}{ No } & \multirow{2}{*}{} \\
\cline { 2 - 5 } & $\mathrm{n}$ & $\%$ & $\mathrm{n}$ & $\%$ & \\
\hline Questionnaires & 59 & 59 & 41 & 41 & 100 \\
\hline Clinic examination & 86 & 86 & 14 & 14 & 100 \\
\hline
\end{tabular}

TABLE III. THE ASSOCIATION BETWEEN THE NUMBER OF TOOTH LOSS WITH TEMPOROMANDIBULAR DISORDERS IN PARTIALLY EDENTULOUS PATIENTS

\begin{tabular}{|c|c|c|c|c|c|c|c|}
\hline \multirow{2}{*}{ TMD } & \multicolumn{6}{|c|}{ The number of tooth loss } & \multirow{2}{*}{ p } \\
\cline { 2 - 7 } & \multicolumn{2}{|c|}{$\mathbf{1 - 5}$} & \multicolumn{2}{|c|}{$\mathbf{6 - 1 0}$} & \multicolumn{2}{|c|}{$>\mathbf{1 0}$} & \\
\cline { 2 - 7 } & $\mathbf{n}$ & $\mathbf{\%}$ & $\mathbf{n}$ & $\mathbf{\%}$ & $\mathbf{n}$ & $\mathbf{\%}$ & \\
\hline Yes & 43 & 79.6 & 13 & 86.7 & 30 & 96.8 & \\
\hline No & 11 & 20.4 & 2 & 13.3 & 1 & 3.2 & \multirow{2}{*}{0.09} \\
\hline & 54 & 100 & 15 & 100 & 31 & 100 & \\
\hline
\end{tabular}

The number of missing posterior teeth was not significant $(\mathrm{p}=0.09)$ by Chi-square test. Analysis of these data are shown there is no association the number of missing teeth with temporomandibular joint disorders.
TABLE IV. THE ASSOCIATION BETWEEN THE NUMBER OF TOOTHLOSS QUADRANTS WITH TEMPOROMANDIBULAR DISORDERS IN PARTIALLY EDENTULOUS PATIENTS

\begin{tabular}{|c|c|c|c|c|c|c|c|c|c|}
\hline \multirow{3}{*}{ TMD } & \multicolumn{8}{|c|}{ The number of tooth loss quadrants } & \multirow{3}{*}{ p } \\
\hline & \multicolumn{2}{|c|}{1} & \multicolumn{2}{|c|}{2} & \multicolumn{2}{|c|}{3} & \multicolumn{2}{|c|}{4} & \\
\hline & $\mathrm{N}$ & $\%$ & $\mathrm{~N}$ & $\%$ & $\mathrm{~N}$ & $\%$ & $\mathrm{~N}$ & $\%$ & \\
\hline Yes & 13 & 65 & 18 & 85.7 & 10 & 83.3 & 45 & 95.7 & \multirow{3}{*}{$0.011^{\mathrm{a}}$} \\
\hline No & 7 & 35 & 3 & 14.3 & 2 & 16.7 & 2 & 4.3 & \\
\hline & 20 & 100 & 21 & 100 & 12 & 100 & 47 & 100 & \\
\hline
\end{tabular}

The number of dental quadrants with missing posterior teeth was significant $(p=0.011)$, it was found that the variable of the number of missing posterior teeth had a statistically significant effect on Temporomandibular joint disorders.

TABLE V. THE ASSOCIATION BETWEEN THE OCCLUSAL SUPPORTS WITH TEMPOROMANDIBULAR DISORDERS IN PARTIALLY EDENTULOUS PATIENTS

\begin{tabular}{|c|c|c|c|c|c|}
\hline \multicolumn{3}{|c|}{ TMD } & Yes & No & \\
\hline \multirow{12}{*}{$\begin{array}{l}\text { Occlusal } \\
\text { Support }\end{array}$} & $\mathrm{A}$ & $\mathrm{N}$ & 35 & 10 & 45 \\
\hline & & $\%$ & 77.78 & 22.22 & 100 \\
\hline & B1 & $\mathrm{N}$ & 7 & 0 & 7 \\
\hline & & $\%$ & 100 & 0 & 100 \\
\hline & B2 & $\mathrm{N}$ & 14 & 4 & 18 \\
\hline & & $\%$ & 77.78 & 22.22 & 100 \\
\hline & B3 & $\mathrm{N}$ & 7 & 0 & 7 \\
\hline & & $\%$ & 100 & 0 & 100 \\
\hline & B4 & $\mathrm{N}$ & 10 & 0 & 0 \\
\hline & & $\%$ & 100 & 0 & 100 \\
\hline & $\mathrm{C}$ & $\mathrm{N}$ & 13 & 0 & 13 \\
\hline & & $\%$ & 100 & 0 & 100 \\
\hline \multicolumn{3}{|c|}{$\mathbf{P}$} & \multicolumn{3}{|c|}{0.089} \\
\hline
\end{tabular}

The chi-square test was no correlation between tooth loss in part to the temporomandibular joint disorder based on the occlusal support occlusal indicated with $\mathrm{p}=0.089$.

\section{DISCUSSION}

This study showed the highest percentage in the group that lost 1-5 teeth. This finding was similar to the Riskesdas data in 2013 which reported national prevalence of DMFT index was 4.6. This means that the average person has 5 teeth loss per person [9].

The prevalence of patients with tooth loss who had signs and symptoms of temporomandibular joint disorder using a questionnaire was $59 \%$ while based on clinical examination the prevalence was $86 \%$. This condition is caused temporomandibular joint disorder has clinical symptoms such as joint pain, clicking during opening or closing of the mouth, restricted mouth opening, mastication disturbance, and headache. However, nonspecific complaints are often expressed by patients for example, neck or shoulder pain, tinnitus, and tenderness in sinus areas, etc $[3,6,10]$.

The present study showed no significant correlation ( $p>0.05$ ) between the amount of tooth loss and temporomandibular joint disorderpatients but patient with signs and symptoms of temporomandibular joint disorder were highest in the group lost more than 10 teeth. The results study showed that signs and symptoms of temporomandibular joints increased in 
individuals who had lost more teeth, this result which is in line with study from Himawan [11].

The main function of the posterior tooth is to assist the breakdown of food during the process of mastication and it is useful for maintaining the vertical dimensions of occlusion. Occlusal posterior tooth contact serves to maintain maximal mandibular stability and minimize pressure on the tooth so as to enable the jaw to be able to receive heavy loads without disturbing its teeth and supporting structures. Unlike the anterior teeth whose primary purpose is not to maintain the vertical dimension but to serve as the mandibular guidance during anterior mandibular movement [11]. This means that the distribution of missing posterior teeth is more important than missing anterior teeth to have an effect on the incidence of temporomandibular joint disorders but in this study, location of tooth loss is not distinguished. Moreover psychological characteristics have been reported to be a potential cause of TMD. Psychological factors associated with pain sensitivity influence the risk of the first onset of temporomandibular joint disorders [4].

The results should have added some information on whether social or psychological factors have a conclusive effect on the association between occlusion and Temporomandibular. Furthermore, there are other known and unknown factors, such as those related to economic conditions, which need to be well-controlled. The above factors should be kept in mind when one considers the present results [4].

In this study, showed that groups who lost posterior teeth in all quadrants of teeth greater percentage of individuals with temporomandibular joint disorders $(95.7 \%)$. Based on chi-square test was found that the variable of the occlusal support had a statistically significant effect on temporomandibular joint disorders $(\mathrm{P}<0.05)$. The decrease of occlusal unit may cause impairment of masticatory performance and initial change in the neuromuscular patern of jaw activity. The distribution and load of occlusal contact seems to be important in relation to craniomandibular function. Relate the long-term effect of missing teeth on altered jaw function, rather than the missing teeth themselves, to the evelpment temporomandibular disorders $[4,13,14]$.

It has also been reported by Wang (2009), inform that when individuals who had lost posterior teeth lost additional posterior teeth adjacent to the primarily lost one(s), the risk of having temporomandibular joint disorders would most likely be lower than it would be for those whose additionally lost posterior teeth were located in a different dental quadrant [4].

The variable of interest was occlusal support, as classified by the Eichner index. The Eichner classification is based on occlusal contact areas in antagonist jaws for thr natural dentition, including fixed dentures. Class A contains four support zones; this means there is a minimum of one tooth in contact between the maxilla and mandible in both the premolar and molar regions on each side. Class B contains three
(B1), two (B2), or one (B3) support zones, or support in the anterior area only (B4). in class $C$, there are no antagonist contacts in dentition [16]. Table 5 showed that all of sample in class B1, B3, B4 and C had temporomandibular joint disorders. Interestingly, when analyzed was found no correlation between occlusal support and 0,089 ) which it was similar to the Hiltunen K (2004) present results because the number of teeth has often served as an indicator of oral health but it cannot describe the functionality of the masticatory system [15].

In other hand based on Mund (2005) study that demonstrates that tooth loss has a different influence on temporomandibular joint disorders in men and women which women did not show any significant relationships between loss of occlusal support and temporomandibular joint disorders while in men demonstrated significant correlation. This difference occurs because of interactions between gender and occlusal support that affect each other on the occurrence of signs and symptoms of temporomandibular joint disorders [16].

The etiology of temporomandibular joint disorders is multifactorial that many risk factors are often associated with the appearance of signs and symptoms of temporomandibular joint disorders. Factors that are often associated include gender and aged. Differences in the level of estrogen is important in the temporomandibular joint disorder based on gender. Estrogen is an important factor in the course of the onset of pain as one of the signs and symptoms of temporomandibular joint disorder $[12,16]$. The higher prevalences temporomandibular joint disorders signs in female may be due to a higher biologic sensitivity to stimuli. Women may detect the signs that men might not notice [16]. In addition, age is a predisposing factor of temporomandibular joint disorders because the frequency and severity of a disease increase with age $[10,11]$. In this study, the relationship between tooth loss and temporomandibular joint disorders was not separately analyzed for gender and age.

\section{ACKNOWLEDGEMENT}

Acknowledgments are addressed to the director of Dental Hospital of Universitas Sumatera Utara for the permission of this study and for all the subjects participated in this study.

\section{REFERENCES}

[1] A. Hatim, G. Jameel, M. Shebab, "Temporomandibular join assesment of pre and post prosthetic treatment of partially edentulous patient (radiographic examination)," Al-Rafidain Dent. J., vol. 11(1), pp. 13-21, 2011.

[2] N. Yanikoglui, U. Guldag, "Analysis of the condyle/fossa relationship in kennedy class I and class II partially edentulous subjects. OHDMBSC, vol. 5(1), pp. 50-56, 2006.

[3] D. Grossi, T. Chaves, A. Oliveira, V. Pedro, "Anamnestic index severity and sign and symptoms of TMD," The J. of Craniomandibular Practice, vol. 24(2), pp. 1-7, 2006.

[4] M. Wang, F. Xue, et al., "Missing posterior teeth and risk of temporomandibular disorders," J. Dent. Res., vol. 88(10), pp. 942-945, 2009 
[5] A. Quaker, Consequences of tooth loss on oral function and need for replacement of missing teeth among patient attending Muhimbili dental clinic, Disertation, 2011, pp. 1-39.

[6] S. Gaphor, S. Hameed, "Prevalence of severity and sex distribution of temporomandibular disorders and other related factors among a sample of Sulaimani University Students," J. Bagh. College Dent., vol. 22(1), pp. 43-49, 2010.

[7] M. Costa, G. Junior, C. Santos, "Evaluation of occlusal factors in patient with temporomandibular joint disorders," Dental Press J. Orthod., vol. 17(6), pp. 61-68, 2010.

[8] I. Uhac, et al., "The effect of occlusal relationships on the occurence of sound in the temporomandibular joint," Coll. Antropo., vol. 26, pp. 285-292, 2002.

[9] Badan Penelitian dan Pengembangan Kesehatan, "Laporan nasional riset kesehatan dasar (RISKESDAS) 2013," Departemen Kesehatan Republik Indonesia, pp. 132-135, 2008.

[10] R.G.K. Shet, et al., "Prevalence of temporomandibular joint dysfunction and its signs among the partially edentulous patients in a village of North Gujarat," The J. of Contemporary Dental Practice, vol. 14(6), pp. 1151-1155, 2013.

[11] L. Himawan, L. Kusdhany, N. Ariani, "Temporomandibular disorders in elderly patients," Med. J. Indonesia, vol. 16(4), pp. 237-239, 2007.

[12] J. Okeson, Management of temporomandibular disorders and occlusion. $6^{\text {th }}$ ed., 2008 , pp. 7-19, 81-88, 112-113, 140-154, 185$187,195,236-240$

[13] U. Soboleva, L. Laurina, A. Slaidina, "Masticatory system-An overview," Baltic Dent. Maxillofacial J., vol. 7(3), pp. 77-80, 2005.

[14] S. Rajesh, "Prevalence of signs temporomandibular joint dysfunction in asymptomatic edentoulus subjects: A crosssectional study," J. Indian Prosthodont. Soc., vol. 10(2), pp. 96$101,2010$.

[15] K. Hiltunen, Temporomandibular disorders in the elderly, Academic Disertation, 2004, pp. 29-33

[16] T. Mundt, et al., "Gender differences in association between occlusal support and signs of temporomandibular disorders: Result of population-based study of health in Pomerania (SHIP)," International J. of Pros., vol. 18(3), pp. 233-239, 2005. 